\title{
An Optimal Schedule for Toll Road Network Construction Based on Greedy Algorithm
}

\author{
$1^{\text {st }}$ Oki Saputra Jaya \\ Department of Mathematics, FMIPA \\ line 3: Universitas Indonesia \\ Depok, Indonesia \\ co-author: oki.saputra@sci.ui.ac.id
}

\author{
$2^{\text {nd }}$ Zuherman Rustam \\ Department of Mathematics, FMIPA \\ Universitas Indonesia \\ Depok, Indonesia \\ Zuherman.Rustam@sci.ui.ac.id
}

\begin{abstract}
Toll road construction is being intensively conducted by the government, especially in Jabodetabek. This makes the schedule of Jabodetabek toll road construction very urgent to solve due to the demands of the target of the completion of the development and it is feared to disturb the existing road condition. Therefore, we conduct research to determine the optimal schedule in construction of Jabodetabek toll road based on Greedy Algorithm. In this study, two methods are used to compare the result, there is greedy algorithm without the deadline and greedy algorithm with the deadline. The determination of toll roads constructed in advance is based on facts in the field, i.e. based on the order of contract status, financial close, and negotiation. Then for the duration of the construction of a toll road depends on the length of the toll road segment that will be built based on the assumption that the length of the toll road construction per $\mathbf{k m}$. Greedy algorithm quickly gets an optimal schedule even if the scale of the road network is large, this is because the greedy algorithm can reduce computational complexity. The problem discussed in this paper is very significant in dealing with the construction of toll road networks in Jabodetabek.
\end{abstract}

Keywords-Greedy Algorithm, Optimal Schedule, Road Network, Toll Road Construction

\section{INTRODUCTION}

The road network is an inseparable part of human life. Humans need a road network as one way to meet the needs of his life. For example like freight logistics, for recreation, for work, etc. Therefore, when the road network is disrupted due to the natural disaster or the construction of new roads, then it will have much impact on human life around it. There are many natural disasters that can cause disruption of road networks, such as earthquakes, floods, landslides and others. As for the construction of new roads, it definitely disrupt the previous road network. When road networks are disrupted due to natural disasters, a fast road repair process is required in order to run normally again. Likewise, when the road network is disrupted due to the construction of new roads, it is necessary the process of rapid road construction so that human life around it can move as usual or even be more efficient.

For many years, complex networks have been studied widely related to properties and application of complex networks [1][2]. It will work well based on robustness for the network [3]. Studies about robustness network focus on two things: enhancement of vital facilities and quick response after the disaster. Many studies on road repair due to natural disasters such as earthquakes, floods, landslides, and others. Research on development has also been done. Research on this has increased in the last decade. Therefore it becomes an important thing for us to do this research. Especially in Indonesia is being incentive in doing national development, one of them is toll road construction. Toll road construction is one of the targets of the Indonesian government in doing national development because the government has the ambition to connect between regions in Indonesia. The toll roads are built like trans-Sumatera toll roads, Papua, Jabodetabek toll roads, and etc. But in this research, we only focus on toll road construction in Jabodetabek.

In the construction and repair of a road, critical links are needed to identify which sections need to be built, and which side is built first. Research on critical links has been done and every researcher has different definitions. Nardelli et al. studied the difference between the length of the path and the link path [1]. Scott et al. defined the network robustness index (NRI) to identify critical links [2]. The NRI is substantially equal to the change in the network-wide travel time when a given link is removed from the network. Hou and Jiang proposed an indirect method to evaluate the relative importance of a link by using link reliability importance [3]. Sohn suggested that the accessibility index could be used to evaluate the significance of highway network links under flood damage [4]. Research similar to this mostly defines the critical links as links to be searched for and can easily add or subtract those links.

Jabodetabek toll road segments that have been planned has three statuses in its implementation to date, namely financial close status, contract status and negotiation status. These three statuses lead us to the definition of critical links in this study. Critical links are links that are determined to begin construction of toll roads and are based on three statuses, namely financial close status, contract status, and negotiation status. This research has aim to get the clear result in the construction of Jabodetabek toll road. Obviously in the sense stamped what roads should be built so as not to cost so much.

In this research, we use a greedy algorithm to determine which segments can be built first, and which segments cannot be built at the same time. We assume the construction of this toll road uses a limited development crew (adjustable). This needs to be done to maintain the efficiency of the 
development undertaken. The greedy algorithm is used here because of its advantages. The advantages of the greedy algorithm can quickly resolve the scheduling issues we carry. In addition, the greedy algorithm is very efficient to reduce the complexity of computing. Therefore it is a right decision for us to use the greedy algorithm to help complete the scheduling of Jabodetabek toll road construction.

We use two variations of the greedy algorithm, i.e greedy algorithm with the deadline and greedy algorithm without the deadline. Although the variations are different, in principle these two variations are the same. Viewed from the same point of complexity, and the timing of completion is not too significant difference. The only difference is there are deadlines and no deadlines. The difference is also seen in the results but still does not show a significant difference. This shows that greedy algorithms can be said to be efficient and stable enough.

\section{METHODS}

This research focuses on optimizing the schedule for a crew/contractor to build Toll road network in Jabodetabek. Crews/contractors can only build links/streets in this case in sequence when the status of the toll road segment is ready. Ready here we assume a road that meets three statuses: contract status, financial close, and negotiation. The note here is that we assume only one crew/contractor of the construction of the toll road segment. Our research aims to minimize the cumulative construction costs of the entire toll road network. A different road construction/construction scheme certainly produces different effects in the results. The complete schema search method requires large workload calculations. In addition, restoration relationships can worsen the toll road network situation due to Braess' paradox. A Greedy algorithm is an algorithm that applies heuristic problem solving that makes optimal local choices at every stage with the goal of finding global optimum. This algorithm performs efficiently for certain scheduling problems [5]. We propose an optimal schedule for the construction of the Jabodetabek toll road network based on the Greedy algorithm because of its advantages. This algorithm aims to obtain an optimal schedule quickly, thus ensuring that the crew/contractor's efforts to develop will result in the construction of the Jabodetabek toll road network that is in line with the government's target. We also prove that the Greedy algorithm applies to our problems in theory. Although our research is more theoretical than practical, it retains the basic characteristics of the traffic. The results can still guide the construction of the Jabodetabek toll road in real life.

In the beginning of this research, greedy algorithms represent identified toll road networks to be constructed in accordance with the assumptions of development status sequences. Namely contract status, financial close status, and negotiation status. The results of this identification are the sequence of completion of the construction of an ascending road segment. Another most obvious outcome of the approach is the creation of isolated subnetworks. Some papers have considered that using a high percentage linkage reduction based on not $100 \%$ can be better. Sullivan et al. [6] extensively investigate this issue. The results show that the most stable range of capacity impairments for critical link rank varies with the level of network connectivity.

The critical links will be used in our Greedy algorithm. Therefore, this section will introduce the definition of critical links. In this study, we focus on the ratio of travel costs in different network states, not to certain travel expenses. The restoration link generates the ratio of system-wide travel time network costs to the worst network is minimal. We define links as these are critical links for the current network. Notations are listed in Table 1 that have been adopted to facilitate the description.

First, we calculate $c_{0}$ as the basis of all calculations. $c_{0}$ can be calculated as follows:

$$
c_{0}=\sum_{j \in\left\{E_{n 1}, E_{r 1}\right\}} t_{j} x_{j}
$$

Where $t_{j}$ is the construction time at link link $j$, and $x_{j}$ is the length of the segment (in KM) on the $j$ link in the initial network according to the Jabodetabek toll road construction model. User equilibrium can be done using TransCAD. The system-wide travel time cost of $c_{e}^{i}$ can be calculated as follows if the construction of link e on the current situation after $(i-1)$ links have been built:

$$
c_{a}^{i}=\sum_{j \in\left\{E_{n i+a}, E_{r i-a}\right\}} t_{j}^{a} x_{j}^{a}
$$

Where $t_{j}^{a}$ is the development time at link $j$, and $x_{j}$ is the length of the segment ( in KM ) on the $j$ link in the network current $j$, according to the Jabodetabek toll road construction model. Critical links can be obtained as follows:

$$
I_{a}^{i}=\frac{c_{a}^{i}}{c_{0}}
$$

\section{Algorithm}

The purpose of our study is to minimize the cumulative travel costs of the entire Jabodetabek toll road network with only one crew/contractor for the construction of the toll road segment. The following assumptions were made before building the model:

(1) The construction of the toll road starting from the toll road section having a contract status (PPJT), then financial close status, and the last is the negotiation status;

(2) Construction of toll roads that run simultaneously can only be done on a maximum of three segments;

(3) Construction of a toll road can be done if another toll lever has been completed and fulfills assumptions 1 and 2;

(4) The time to build one-kilometer toll road is 20 days. From this assumption, for each development step, our objective function and set of constraints are formulated as follows :

Table 1. Notation descriptions

\begin{tabular}{|c|l|}
\hline Notation & \multicolumn{1}{c|}{ Definition } \\
\hline$E$ & $\begin{array}{l}\text { The set of all links in the Jabodetabek toll road } \\
\text { network }\end{array}$ \\
\hline$E_{\text {normal }}$ & $\begin{array}{l}\text { The set of normal / functional links in the road } \\
\text { network, the abbreviation is } E_{n}\end{array}$ \\
\hline$E_{\text {construction }}$ & $\begin{array}{l}\text { The set of abnormal links (to be built in the road } \\
\text { network), the abbreviation is } E_{r}\end{array}$ \\
\hline
\end{tabular}




\begin{tabular}{|c|l|}
\hline$E_{n i}$ & $\begin{array}{l}\text { The set of normal links before the } \dot{L} \text {-link construction } \\
\text { on the road network }\end{array}$ \\
\hline$E_{r i}$ & $\begin{array}{l}\text { The set of abnormal links prior to the construction of } \\
\text { the } i \text {-th link in the road network }\end{array}$ \\
\hline$C_{0}$ & $\begin{array}{l}\text { The cost of the entire wide-system trip is in its initial } \\
\text { state }\end{array}$ \\
\hline$c_{a}^{i}$ & $\begin{array}{l}\text { The entire system of travel expenses after link } \\
\text { building } i \text { and } e \text { links ends }\end{array}$ \\
\hline$I_{a}^{i}$ & $\begin{array}{l}\text { Ratio } c_{i} \text { ke } c_{i}, \text { represents the importance of the given } \\
\text { e link }\end{array}$ \\
\hline$i$ & $\begin{array}{l}\mathrm{i}=1,2,3, \ldots, \mathrm{M} ; \mathrm{m} \text { is equal to the number of links } \\
\text { belonging } E_{r}\end{array}$ \\
\hline
\end{tabular}

$$
\text { s.t } \sum_{a} I_{a}^{i} \leq 1, a \in E_{r}
$$

$$
\sum_{a} I_{a}^{i} \leq 1, i_{a}^{i} \in\{0,1\}
$$

Where $I_{a}^{i}$ is notated as follows :

$$
I_{a}^{i}=1 \text {, link e is built entirely in step } i
$$$$
I_{a}^{i}=0 \text {, else }
$$

Equation 5 shows that the crew/contractor can only fix one link in one step. Equation 6 shows that each link to be built is only one step. In particular, we hope that each crew/contractor step can reduce the overall cost of road network travel to optimum. The final construction schedule obtained by each step decision is also optimal. In other words, the construction of our toll-road crew/contractor section makes the best choice according to the current state of affairs at every step, and each step of the best option makes the final global optimal choice as shown in equation 8 . The left side of Equation 8 Shows a global solution, in order to improve the optimization variable. The right-hand side of equation 8 shows the sum of each optimal local solution. We can achieve a global optimal solution that is only through the local optimal choice when equation 8 is true. Relevant evidence will be given in the next section.

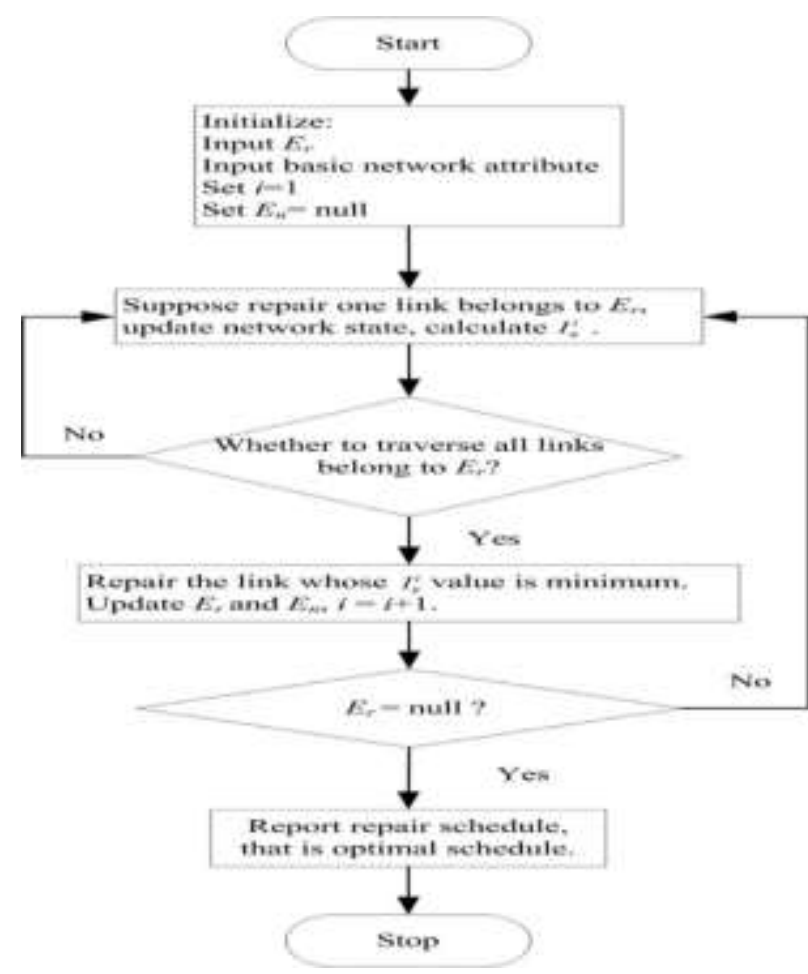

Fig. 1. Flowchart of Greedy Algorithm

The exhaustive search algorithm is definitely feasible to solve the problem, but it will take a lot of time. Therefore, we propose Greedy's algorithm to solve our problem. We provide important link priority in accordance with the Greedy principle. The critical link is determined by Equation 4. That means Equation 4 is a selection function, which is determined by linking one link to another link to be built each step. We build critical links from the rest of $E_{r}$ until all the links are built. However, critical link ranking cannot remain unchanged over time due to changes in the road network. Therefore, updating the critical link rank after link restoration is required. The Greedy algorithm procedure will be described in the following paragraph, and also illustrated by flowchart in Fig. 1

\section{Greedy Algorithm Procedure:}

1. Initialization: Define $E_{r}$ and $E_{n}$; Input of basic network path attributes such as time travel (start time and stop time), capacity of links.

2. Calculate the value of $I_{a}^{i}$ from each link belonging to $E_{r}$

3. Sort links based on the value of $I_{a}^{i}$ and based on completion time/finish of a road construction

4. Runs based on critical links, then to the next link based on the order of workmanship

5. Update the initial value of the $E_{r}$ and $E_{n}$ network paths

6. Repeat step 2 to 5 until $E_{r}=$ null

7. We got the optimal schedule

\section{RESULTS AND DISCUSSION}

We propose an optimal schedule for the construction of the Jabodetabek toll road network based on the greedy algorithm on the Jabodetabek toll road network (Fig. 2), which contains 24 nodes and 17 links. The network of 
Jabodetabek toll road construction is a new experimental network in transportation research. The length of development on a road segment is shown in Table 2, and the length of the network / a segment is also shown in Table 3.

The link capacity reduction range of between $80 \%$ and $75 \%$ is the most appropriate for the test network according to the study of Sullivan et al. [6] and the connectivity of the Jabodetabek toll road network. Two trials in the exam are as follows. The first experiment was an experimental greedy algorithm with deadlines. The first experiment assumes that 8 links ready to be built within the Jabodetabek toll road network assuming that after the toll road with the status of the contract has been implemented, two toll roads are jointly constructed so that the other toll roads are affected (Table 2). The second experiment was an experimental greedy algorithm without a deadline. The second experiment assumes that 10 links ready to be built within the Jabodetabek toll road network assuming that after the toll road with the status of the contract has been implemented, two toll roads are jointly undertaken to affect the other toll roads (Table 3). We provide all the schedules for comparison.

\section{First Experiment ( Greedy Algorithm With Deadline )}

Suppose that the links $a 1, a 2, a 3, a 4, a 5, a 6, a 7$ and $a 8$ on the Jabodetabek toll road network (Fig. 2) are ready to construct/construct new toll roads. $80 \%$ reduction in capacity. We get $\operatorname{Er}=\{a 1, a 2, a 3, a 4, a 5, a 6, a 7, a 8\}$, and then calculate the value of $I_{a}^{1}$ for each broken link belonging to Er. Table 2 shows that in the circumstances, improvement of a2 relationship will enable development work to achieve maximum results. After the improvement of $a 2$ relations, the initial state of the network also changes due to the interaction between links. Therefore, we can not fix the $a 1$ relationship after fixing the $a 2$ relationship. We must re-evaluate the relative importance of the links that have been built after the restoration of Link $a 2$. That is, we must calculate the value of $I_{a}^{2}$ for each broken link belonging to $E_{r 2}$, and then decide which link to fix. In this case, the link for accidental improvement $a 1$, which is the optimal choice. From this analogy, we can finally get the optimal schedule as: $a 6 \rightarrow a 7 \rightarrow a 1 \rightarrow a 8 \rightarrow a 4 \rightarrow a 5 \rightarrow a 3 \rightarrow a 2$. The ranking of critical relationship changes with changes in the road network is shown in Table 2. Table 2 shows that critical link rank almost nearly changed after link restoration link. In toll road network is influenced by each long distance of toll road segment. We pay attention to focus on the situation after restoration Link $a 2$. In our study, we can predict links will cause the cost of travel across the network significantly higher. With regard to scheduling the construction of toll roads based on the Greedy algorithm, we ensure that the limited resources on development will play the greatest role in every stage of development. The optimal development schedule for the current situation, but also the best for the global situation. Our schedule considers Link interaction. Therefore, the optimal schedule is: $a 6 \rightarrow a 7 \rightarrow a 1 \rightarrow a 8 \rightarrow a 4 \rightarrow a 5 \rightarrow a 3 \rightarrow a 2$ assuming we have only one crew.

\section{Second Experiment (Greedy Algorithm Without Deadline)}

Suppose that the links $a 1, a 2, a 3, a 4, a 5, a 6, a 7, a 8, a 9$ and $a 10$ on the Jabodetabek toll road network (Fig. 3) are ready to construct / construct new toll roads. Assuming that after the toll road with the status of the contract has been implemented, there are two toll roads that are done simultaneously so that impact on other toll roads (Table 3), according to the Greedy algorithm, our optimal schedule is $a 2 \rightarrow a 6 \rightarrow a 8 \rightarrow a 9 \rightarrow a 5$

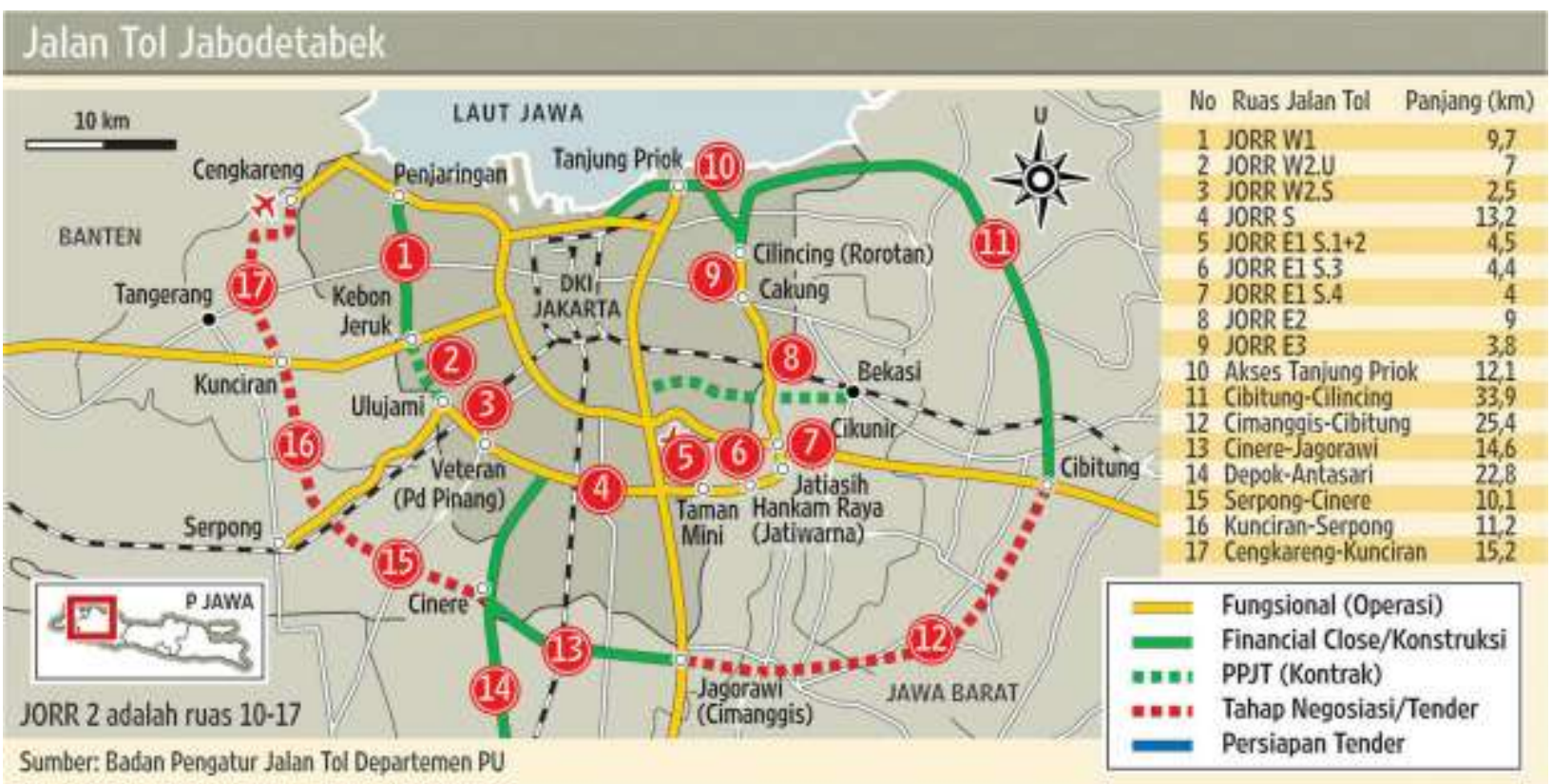

Sumber: Badan Pengatur Jalan Tol Departemen PU 
Table 2. Optimal ordering of Jabodetabek toll road schedules

\begin{tabular}{|c|c|c|c|c|}
\hline No & Segments of Toll Road Network & Length (KM) & Deadline (Number of Month) & Profit \\
\hline 10 & Akses Tanjung Priok (a1) & 12,1 & Desember 2018 (35) & 11,763 \\
\hline 11 & Cibitung-Cilincing (a2) & 33,9 & Desember 2019 (47) & 33,194 \\
\hline 12 & Cimanggis-Cibitung (a3) & 25,4 & Desember 2019 (47) & 24,871 \\
\hline 13 & Cinere-Jagorawi (a4) & 14,6 & Desember 2018 (35) & 14,194 \\
\hline 14 & Depok-Antasari (a5) & 22,8 & Desember 2018 (35) & 22,167 \\
\hline 15 & Serpong-Cinere (a6) & 10,1 & Desember 2017 (23) & 9,679 \\
\hline 16 & Kunciran-Serpong (a7) & 11,2 & Desember 2018 (35) & 10,889 \\
\hline 17 & Cengkareng-Kunciran (a8) & 15,2 & Desember 2018 (35) & 14,778 \\
\hline
\end{tabular}

Table 3. The Length of each Network and Time for development

\begin{tabular}{|c|c|c|c|c|}
\hline No & Segments of Toll Road Network & Length $(\mathrm{KM})$ & Start Time & Finish Time \\
\hline 1 & Jorr W.1 & 9,7 & 40 & 324 \\
\hline 2 & Jorr W.2.U & 7 & 0 & 140 \\
\hline 10 & Akses Tanjung Priok & 12,1 & 40 & 280 \\
\hline 11 & Cibitung-Cilincing & 33,9 & 280 & 958 \\
\hline 12 & Cimanggis-Cibitung & 25,4 & 858 & 1366 \\
\hline 13 & Cinere-Jagorawi & 14,6 & 140 & 432 \\
\hline 14 & Depok-Antasari & 22,8 & 234 & 690 \\
\hline 15 & Serpong-Cinere & 10,1 & 432 & 634 \\
\hline 16 & Kunciran-Serpong & 11,2 & 634 & 858 \\
\hline 17 & Cengkareng-Kunciran & 15,2 & 690 & 994 \\
\hline
\end{tabular}

\section{CONCLUSION}

The essence of the problem we raised was how to allocate limited resources to achieve similar objectives with the study of the construction of existing toll roads in Indonesia, not just Jabodetabek, even we hope to be applied in other parts of the world according to the target given by the government. How limited resources can be allocated to minimize cumulative travel costs across the network. We define a critical link for our purposes, which considers Link's interactions. We fix the important links to quickly achieve our goal based on the greedy algorithm, which aims to get a global optimal solution that uses the optimum local solution. The broken link repair order is the optimal schedule.

Our concern is that the construction of the Jabodetabek toll road network is completed according to the target/deadline of the Ministry of Public Works. Therefore, the critical links we define are suitable for the construction of toll road networks. The core link rank to be built is clearly changed due to the interaction between links after the link is fixed. Case studies clearly show this situation. That is, core link evaluation should be dynamic. The case studies also show that the effect of repairing two links is not necessarily better than the effect of fixing one link due to Braess' paradox. If the wrong link is selected for repair, the road network condition will worsen rather than increase. Our research can really avoid such bad decisions. Evaluate the core links before each development step fully utilizes the limited resources. Although our optimal schedule assumes that we can only fix one link for each step, the operation can be extended to fix two or more links for each step rather than recalculate. For example, the optimal schedule is a $\rightarrow$ a7 $\rightarrow$ a $\rightarrow$ a $8 \rightarrow$ a $4 \rightarrow$ a5 $\rightarrow$ a $3 \rightarrow$ a 2 because this case shows that we have only one crew/contractor. Various solutions are available for the road network construction schedule. The greedy algorithm we apply can obtain a global optimal schedule through the local optimal schedule, which greatly 
reduces computational

computational efficiency.

\section{REFERENCES}

[1] Gao ZK, Jin ND., "A directed weighted complex network for characterizing chaotic dynamics from time series", Nonlinear analysis Real World Applications, vol. 13, pp. 947-952, 2012.

[2] Gao ZK, Yang YX, Fang PC, Jin ND, Xia CY, Hu LD., "Multi-frequency complex network from time series for uncovering oil-water flow structure. Scientific Reports. 2015; 5 :

[3] Iyer S, Killingback T, Sundaram B, Wang Z. Attack Robbustness and Centrality of Complex Networks. Plos One. 2013;8

[4] Corley HW, Sha DY. Most vital links and nodes in weighted networks. Operations Research Letters. 1982; 1: 157 \pm 160

[5] Scott DM, Novak DC, Aultman-Hall L, Guo F., "Network Robustness Index: A new method for identifying critical links and evaluating the performance of transportation networks", Journal of Transport Geography, vol. 14, pp. 215-227, 2006.
[6] Hou LW, Jiang F., "Study on the Relative Importance of Links in Urban Roads Network", Systems Engineering-Theory Methodology Application, vol.13, pp. 425-428, 2004.

[7] Sohn J., "Evaluating the significance of highway network links under the flood damage: An accessibility approach", Transportation Research Part a Policy \& Practice, vol. 40, pp. 491-506, 2006.

[8] Ying KC, Lin SW, Huang CY., "Sequencing single-machine tardiness problems with sequence dependent setup times using an iterated greedy heuristic", Expert Systems with Applications, vol. 36, pp. 7087-7092, 2009.

[9] Sullivan JL, Novak DC, Aultman-Hall L, Scott DM., "Identifying critical road segments and measuring system-wide robustness in transportation networks with isolating links: A link-based capacity-reduction approach", Transportation Research Part a Policy \& Practice,vol. 44, pp. 323-336, 2010.

[10] GuangQuan Lu, Yin Xiong, Chuan Ding \& Yunpeng Wang, "An Optimal Schedule for Urban Road Network Repair Based on Greedy Algorithm", Journal of Optimization, pp. 1-15, 2016. 